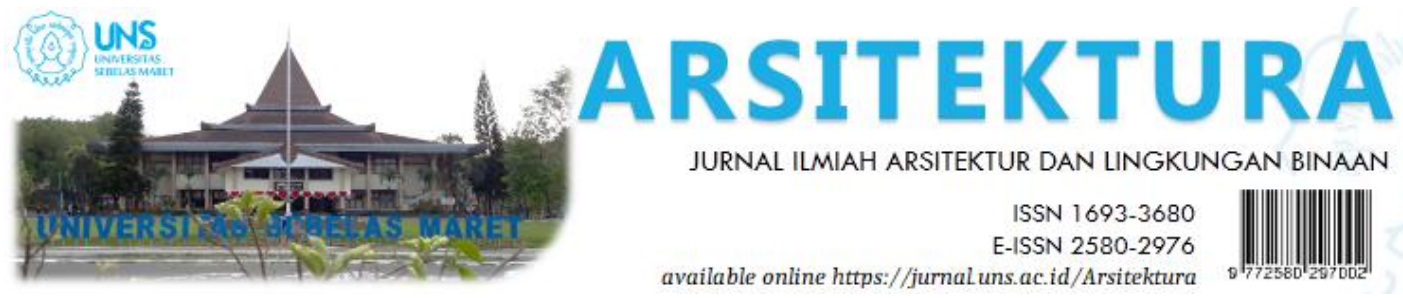

Volume 19 Issue 2 October 2021, pages: 317-326

\title{
Adaptasi Ruang Berdasarkan Perilaku Penghuni Sub Komunal Rumah Instan Sederhana Sehat (RISHA), Semanggi, Surakarta
}

\author{
Space Adaptation Based on The Behavior of Sub Communal \\ “Rumah Instan Sederhana Sehat (RISHA)" Residents, \\ Semanggi, Surakarta
}

\author{
Fauzan Ali Ikhsan, Anita Dianingrum, Kusumaningdyah Nurul Handayani, \\ Pratiwi Anjar Sari, Mohamad Muqoffa, Titis Srimuda Pitana \\ Urban Rural Desain Conservation Research Group, Department of Architecture, \\ Engineering Faculty Sebelas Maret University \\ fauzan@ft.uns.ac.id
}

DOI: https://doi.org/10.20961/arst.v19i2.55476

Received:September 30,2021 Revised:October 29,2021 Accepted:October 29,2021 Available online:October 30,2021

\begin{abstract}
Sub Communal RISHA is a pilot project from the central government in collaboration with the Surakarta City Government as a solution for structuring slum settlements in Surakarta. The RISHA method facilitates the construction and installation process due to the use of a modular precast system which is also more flexible and efficient both in terms of construction time and the use of construction materials. The purpose of this research is to identify the space adaptation of Sub Communal RISHA based on behavior of residents. This research was conducted with a qualitative descriptive method. The research location is in the area of $R W 06$ Rusunawa Semanggi Surakarta and the time of data collection was carried out in the period May-August 2021. Primary data was taken with several techniques, observation and Forum Group Discussion (FGD) method. The analysis was carried out using data triangulation techniques. The use of this analysis technique aims to combine all data to produce accurate and comprehensive conclusions. The results showed that there are two adaptation carried out by the residents of Sub Communla RISHA, namely adaptation strategies by adjustment and adaptation strategies based on reactions.
\end{abstract}

Keywords: adaptation; home; Sub Komunal RISHA; Semanggi

\section{PENDAHULUAN}

Urbanisasi mengakibatkan populasi penduduk di kota terus meningkat. Berdasarkan Global Report on Human Settlement 2005, proyeksi jumlah penduduk di perkotan sekitar 2,8 miliar orang (40 \% dari populasi dunia ) akan membutuhkan perumahan dan layanan kota pada tahun 2030. Untuk mengakomodasi peningkatan jumlah rumah tangga selama 25 tahun kedepan, akan dibutuhkan 35.1 juta unit perumahan pertahun. Estimasi ini akan diterjemahkan ke dalam penyelesaian 96.150 unit rumah per hari atau 4000 per jam. Angka angka tersebut tidak termasuk penggantian persediaan perumahan yang buruk dan dibawah standar (UN-Habitat, 2005). 
Pola pembangunan perumahan yang berkembang di Indonesia saat ini yang didominasi oleh pengadaan melalui mekanisme pasar formal dan fasilitas kredit belum dapat menjangkau masyarakat berpenghasilan rendah (MBR). Tentu bagi masyarakat berpenghasilan rendah (MBR), mekanisem dan fasilitas yang ditawarkan sangat sulit untuk dijangkau melihat pekerjaan dan penghasilan mereka yang tidak menentu. Sehingga mereka tidak mempunyai kesempatan dan pilihan untuk memenuhi kebutuhan hunian yang layak. Membangun rumah secara mandiri/swadaya menjadi pilihan bagi masyarakat berpenghasilan rendah terutama mereka yang berada di perkotaan. Perumahan yang dibangun oleh masyarakat secara swadaya sangat berpotensi menjadi permukiman kumuh karena kondisinya yang cenderung tidak layak akibat terbatasnya kemampuan masyarakat. Fenomena tersebut seringkali tidak bisa terhindarkan terutama di kota-kota besar tak terkecuali kota Surakarta.

Surakarta merupakan salah satu kota besar di Jawa Tengah yang juga dihadapkan dengan penanganan perumahan/permukiman kumuh. Berdasarkan data identifikasi tahun 2016, terdapat 359,55 hektar wilayah di Surakarta yang teridentifikasi merupakan wilayah kumuh dan Kawasan Semanggi masuk menjadi bagiannya dan menjadi prioritas pemerintah Suarakrta.

Menurut data dari Kotaku tahun 2018, kawasan kumuh di Semanggi memiliki luas 76,03 hektar yang dihuni kurang lebih sekitar $10.204 \mathrm{KK}$ atau 31.518 jiwa dengan dominasi masyarakat berpenghasilan rendah (MBR) (sekitar 39,96\% atau $4.078 \mathrm{KK}$ ) yang berprofesi pada sektor informal.

Rumah Instan Sederhana Sehat (RISHA) adalah teknologi membangun rumah sederhana sehat yang dikembangkan oleh Puslitbang Perumahan dan Permukiman, Kementerian Pekerjaan Umum dan Perumahan Rakyat (PUPR). RISHA menggunakan teknologi beton pracetak dengan persyaratan teknis mengacu Kepmen Kimpraswil No.403/KPTS/M/2002 tentang Pedoman Teknis Rumah Sederhana Sehat. Pembangunan rumah sederhana sehat dengan teknologi RISHA merupakan upaya untuk menjawab tantangan pembangunan rumah sederhana dengan cepat dan biaya produksi rendah.

Beberapa penelitian tentang rumah sederhana sehat bagi masyarakat berpenghasilan rendah telah dilakukan. Penelitian RISHA yang berkaitan dengan teknologi material memberikan pemahaman bahwa RISHA dapat menggunakan material beton dan logam (Wibowo, 2018). Efektifitas pembangunan RISHA (Kamsuta et al., 2020), pemanfaatan teknologi RISHA untuk penanganan permukiman kumuh (Pramantha, 2019), penelitian kenyamanan thermal pada RISHA (Fang et al., 2020), penelitian tentang proses desain Risha ((Noverti et al., 2014), penelitian tentang pemanfaatan teknologi Risha untuk penyediaan rumah di daerah bencana(Hijah \& Komarudin, 2019)(Sushanti et al., 2020).

Penelitian yang berkaitan dengan arsitektur perilaku terutama yang membahas proses adaptasi penghuni Sub Komunal RISHA selama ini belum pernah dilakukan. Penelitian dengan pendekatan arsitektur perilaku yang sudah ada Sebagian besar mengambil kasus rumah susun sewa (rusunawa). Penelitian tersebut mengungkap tentang kepuasan penghuni rusunawa (Subagijo \& Suhartono, 2018), kemudian penelitian tentang adaptasi penghuni rusunawa dan transformasi ruang (Ghozali, 2018), (Luthfiah, 2010).

Pengertian adaptasi menurut Kamus Besar Bahasa Indonesia adalah sebuah respon individu sebagai usaha penyesuaian terhadap lingkungan baru untuk mengurangi konflik atau ketidaksesuaian dengan lingkungannya sebagai upaya untuk meningkatkan harmoni. Strategi adaptasi individu terhadap lingkungannya dibedakan menjadi tiga macam (Irwin Altman, Amos Rapoport, 1980), yaitu: (1) Adaptasi by adjusment, yaitu suatu trategi tindakan mengurangi konflik melalui penyesuaian diri, sehingga tercapai keselarasan tanpa melakukan perubahan fisik lingkungan; (2) Adaptasi by reaction, yaitu suatu strategi untuk melakukan penyesuaian diri dengan lingkungannya dengan melakukan perubahan-perubahan fisik; (3) Adaptasi by withdrawal, yaitu strategi adaptasi dengan melakukan migrasi atau pindah ketempat lain untuk mengurangi tekanan/konflik dengan lingkungannya. 
Penelitian tentang adaptasi penghuni Sub Komunal RISHA cukup menarik untuk dilakukan identifikasi. Keterbasan variasi modul desain dan luasan ruang pada unit hunian RISHA memberikan tantangan tersendiri bagi penghuni untuk menjalankan aktivitas kehidupan sehari-hari. Penelitian ini berusaha mengungkap adaptasi ruang yang dilakukan oleh penghuni RISHA sebagai sebuah respon penyesuaian terhadap lingkungan baru. Hasil penelitian tentang adaptasi ruang penghuni Sub Komunal RISHA, Semanggi diharapkan dapat memberikan masukan bagi para stakeholder terkait untuk pengembangan desain unit hunian Sub Komunal RISHA pada masa yang akan datang.

\section{METODE}

Penelitian diakukan dengan metode diskriptif kualitatif. Lokasi penelitian berada di Sub komunal Risha RW. 06 Rusunawa Semanggi Surakarta. Waktu pengambilan data dilakukan dalam rentang bulan Mei-Agustus 2021. Data primer diambil dengan beberapa teknik, yaitu: (1) Observasi lapangan untuk mengetahui kondisi lingkungan perumahan/ permukiman di Sub Komunal RISHA, (2) Metode Forum Group Discussion (FGD) untuk menggali preferensi penghuni melalui Evaluasi Purna Huni (EPH) terhadap beberapa unit hunian warga (purposive sampling). FGD dilakukan dengan beberapa perwakilan warga penghuni Sub Komunal RISHA.

Analisa dilakukan dengan teknik triangulasi data. Teknik ini digunakan untuk menganalisis data dari berbagai sumber data yang meliputi hasil data observasi dan Forum Group Discussion (FGD). Penggunaan teknik analisa ini bertujuan untuk mengkombinasikan semua data agar dapat menghasilkan simpulan yang tepat dan komprehensif.

\section{HASIL DAN PEMBAHASAN}

Hunian sementara Sub Komunal RISHA Semanggi merupakan pilot proyek dari pemerintah pusat yaitu Kementerian PUPR bekerja sama dengan Pemerintah Kota Surakarta sebagai salah satu solusi pengembangan hunian untuk penataan permukiman kumuh. Hal ini sejalan dengan Peraturan Menteri No. 14/PRT/M/2018 tentang
Pencegahan dan Peningkatan Kualitas Terhadap Perumahan dan Permukiman Kumuh yang mewajibkan Pemerintah Daerah untuk mewujudkan permukiman yang layak huni, sehat, aman, harmonis dan berkelanjutan sebagai pelaku utama penanganan. Menurut SK Wali Kota Surakarta Nomor: 413.21/38.3/1/2016 tentang Penetapan Lokasi Kawasan Lingkungan Perumahan dan Permukiman Kumuh di Kota Surakarta, dengan total luas sebesar 359,55 Ha, dimana Kawasan Semanggi menjadi salah satu prioritas utama penanganan kumuh pada tahun 2018. Identifikasi tersebut juga tertuang pada memorandum Program Rencana Kawasan Permukiman Kumuh Perkotaan (RKPKP).

Pembangunan hunian RISHA sebagai Huntara, dilaksanakan dengan pendanaan dari APBN 2018. Pelaksanaan konstruksi dilakukan oleh kontraktor yang ditentukan oleh Balitbang PUPR. Pada tahun 2019 pembagunan Sub Komunal RISHA telah selesai dan telah diresmikan oleh Pemerintah Kota Surakarta dan Puslitbang Perumahan dan Permukiman Kementerian Pekerjaan Umum dan Perumahan Rakyat (PUPR). Setelah proses peresmian pengelolaan akan diserahkan kepada Pemerintah kota, kemudian pemerintah kota menyewakan kepada warga. Namun Penempatan Warga Terdampak Proyek (WTP) pada huntara yang dibangun ini tidak dipungut sewa, sewa ditanggulangi melalui APBD kota Surakarta.

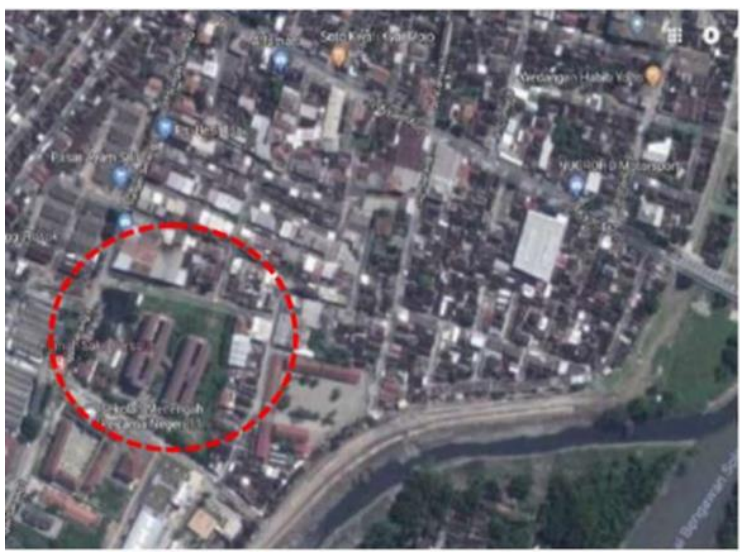

Gambar 1. Lokasi RISHA sub komunal Rusunawa RW 06 Semanggi Surakarta

Sumber: Dokumen LARAP Rencana Penataan Kawasan Kumuh Semanggi RW 23, 2018 
RISHA dibangun untuk menyediakan hunian sementara bagi warga yang terkena dampak penataan bantaran Sungai Bengawan Solo. Hunian RISHA yang dibangun di Surakarta merupakan unit hunian yang dikelompokkan secara komunal kecil (komunal A, B, C) yang terdiri dari 2 lantai dengan tipe luas hunian sebesar $36 \mathrm{~m}^{2}$. Keseluruhan unit hunian yang dibangun sejumlah 56 unit.

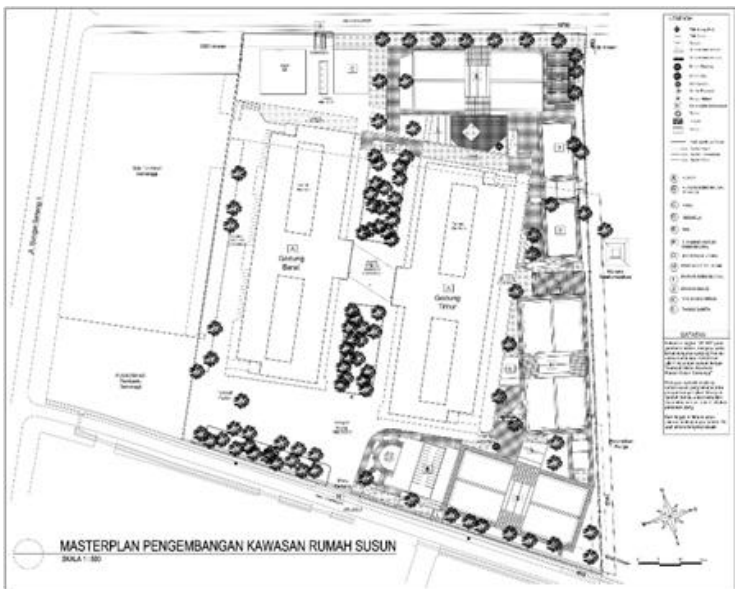

Gambar 2. Siteplan Huntara sub komunal RISHA Komplek Rusunawa RW 06 Semanggi

Sumber: Dokumen LARAP Rencana Penataan

Kawasan Kumuh Semanggi RW 23, 2018

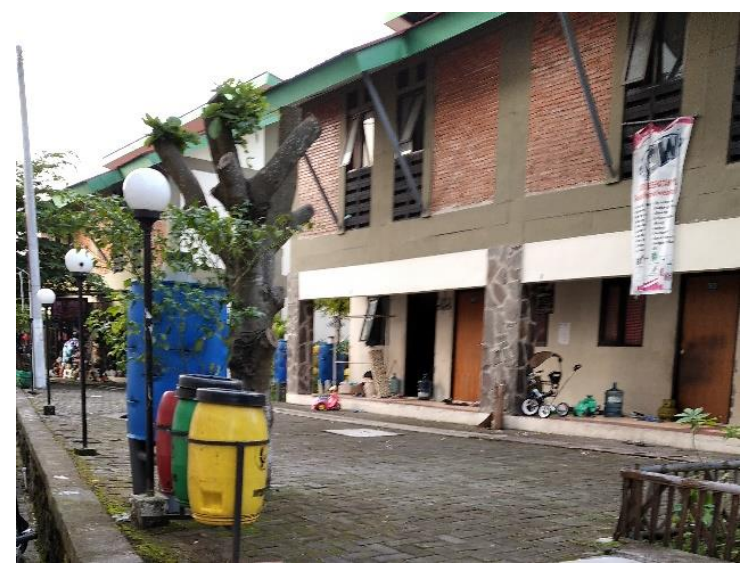

Gambar 3. Suasana Lingkungan Sub Komunal RISHA Semanggi.

Hunian Sub Komunal dibangun dengan metode konstruksi RISHA (Rumah Instan Sederhana Sehat), dimana metode ini menggunakan sistem pracetak modular yang fleksibel dan efisien, sehingga proses pembangunan dan pemasangannya lebih mudah dan cepat. Hunian Sub Komunal juga sudah dilengkapi dengan fasilitas seperti taman, tempat parkir, ruang Bersama, tempat ibadah dan tempat untuk berdagang.
Perubahan lingkungan fisik hunian memiliki pengaruh terhadap perilaku penghuni Sub komunal RISHA baik secara langsung maupun tidak langsung. Secara fisik, lingkungan perumahan dan permukiman para penghuni mengalami perubahan, dimana awalnya masyarakat tinggal pada unit hunian horizontal (landed housing) menjadi lingkungan permukiman vertikal (bangunan dua lantai). Hal ini memberikan implikasi perubahan perilaku penghuni sebagai sebuah respon untuk penyesuaian para penghuni di lingkungan hunian yang baru.

Rata-rata penghuni Sub Komunal RISHA Semanggi bekerja pada sektor informal, sehingga kemampuan dapat dikategorikan sebagai masyarakat berpenghasilan rendah. Sehingga upaya penyesuaian lingkungan fisik dilakukan sesuai kemampuan ekonomi masingmasing.

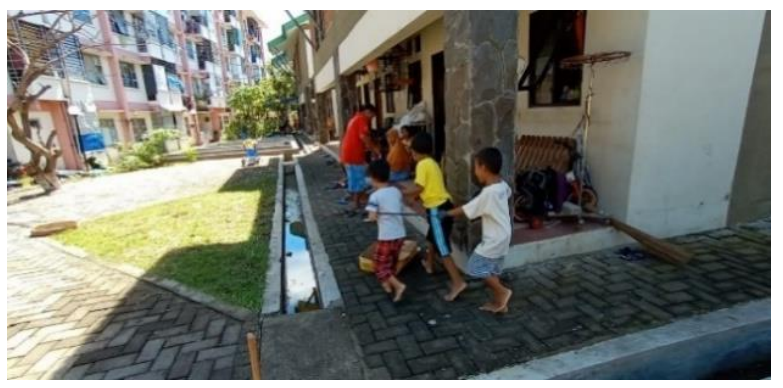

Gambar 4. Suasana halaman depan sebagai tempat bermain anak.

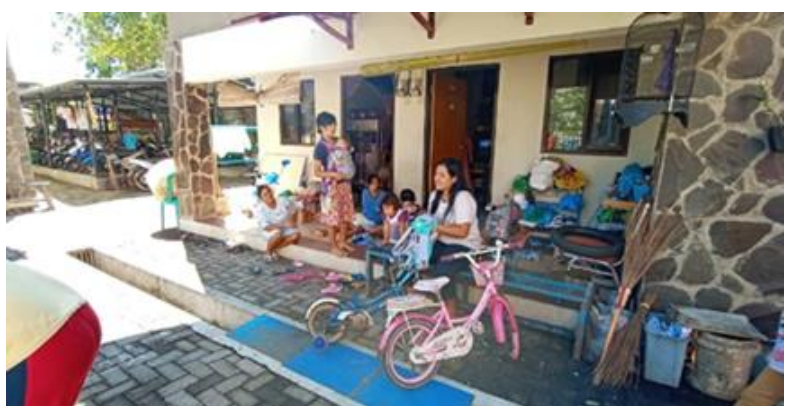

Gambar 5. Suasana halaman depan sebagai tempat komunal.

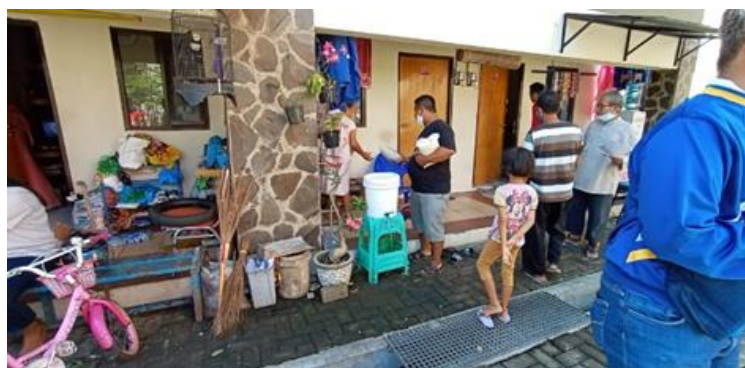

Gambar.6 Suasana teras sebagai tempat menyimpan barang dan berjualan 


\subsection{Setting Ruang dan Aktivitas Penghuni pada Unit Hunian Sub Komunal RISHA}

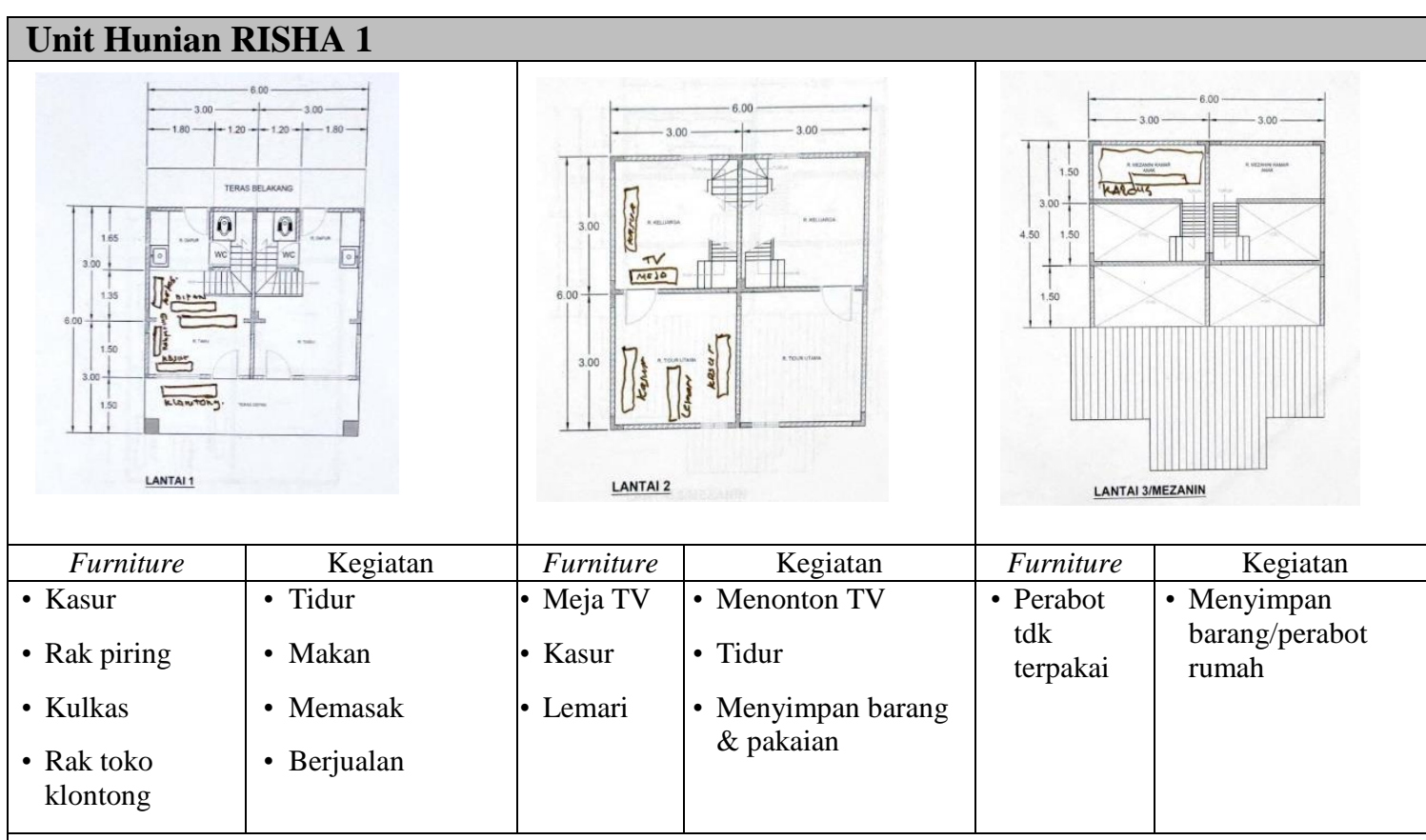

Pada kasus RISHA 1, jumlah penghuni RISHA adalah lima orang. Pekerjaan kepala keluarga adalah buruh pasang tenda. Pada lantai 1, penghuni memfungsikan teras di depan kamar sebagai tempat usaha warung kelontong sederhana yang menjual kebutuhan sehari-hari. Penghuni melakukan adaptasi by reaction dengan menambah kanopi seng di depan teras agar mengurangi resiko percikan air hujan. Penghuni memanfaatkan ruang tamu menjadi ruang multi fungsi yaitu digunakan untuk ruang tidur pada malam hari. Untuk lantai 2, penghuni membuat sekat semi permanen pada kamar tidur dengan menggunakan lemari kayu, sehingga didalam kamar masih tercipta privasi meskipun digunakan oleh dua orang. Penghuni juga membuat ruang keluarga menjadi ruang multifungsi, dimana saar malam hari dapat digunakan sebagai ruang tidur. Sementara itu, ruang mezanin kamar anak digunakan untuk menyimpan barang yang tidak digunakan.

\section{Unit Hunian RISHA 2}

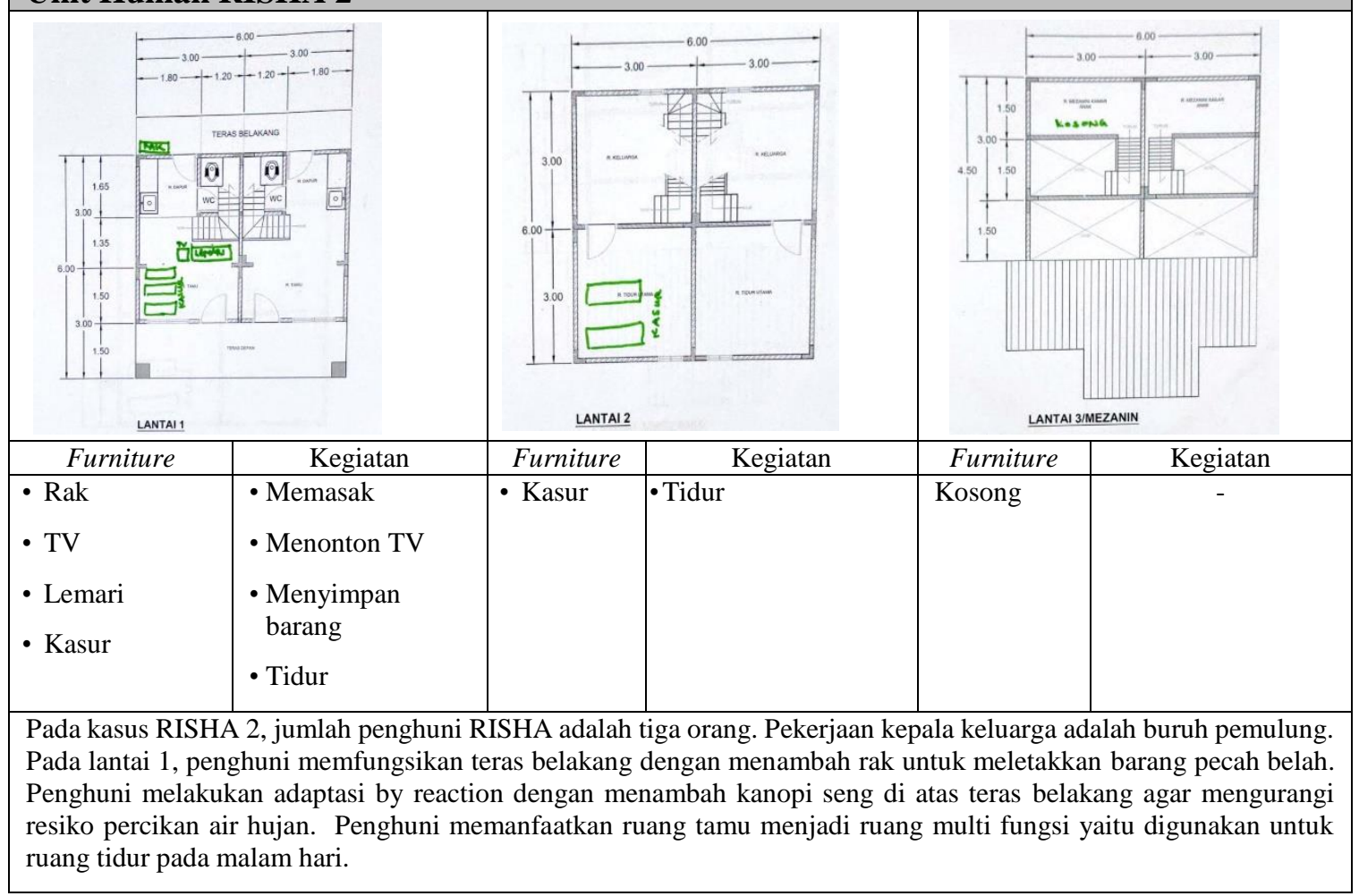




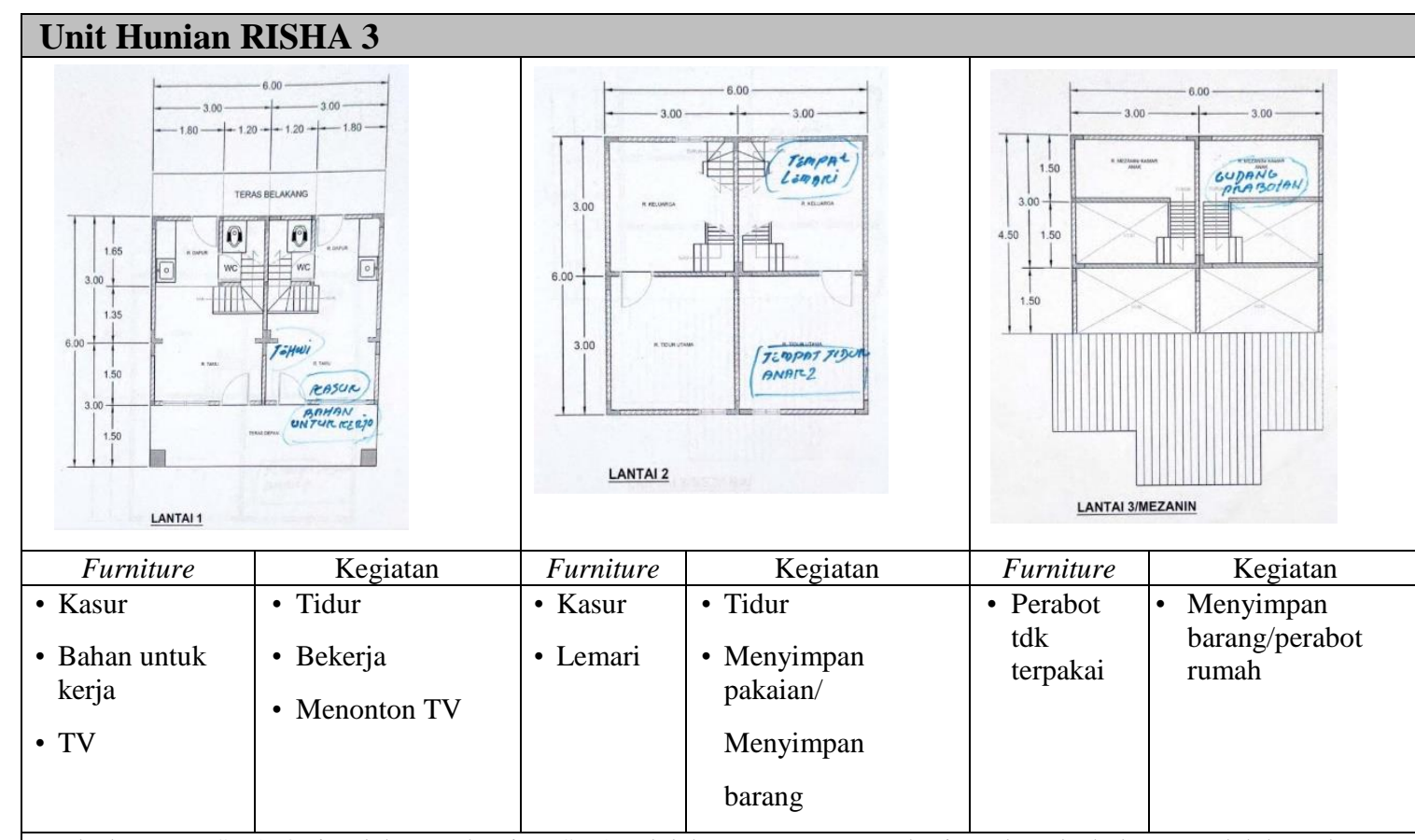

Pada kasus RISHA 3, jumlah penghuni RISHA adalah enam orang. Pekerjaan kepala keluarga adalah pedagang pembuat pentol. Pada lantai 1, penghuni memfungsikan teras di depan kamar sebagai tempat bekerja memproduksi pentol. Penghuni melakukan adaptasi by reaction dengan menambah kanopi seng di depan teras agar mengurangi resiko percikan air hujan. Penghuni memanfaatkan ruang tamu menjadi ruang multi fungsi yaitu digunakan untuk ruang tidur pada malam hari. Untuk lantai 2, penghuni meletakkan lemari di ruang keluarga untuk menyimpan barang. Sementara itu, ruang mezanin kamar anak digunakan untuk menyimpan barang yang tidak digunakan.

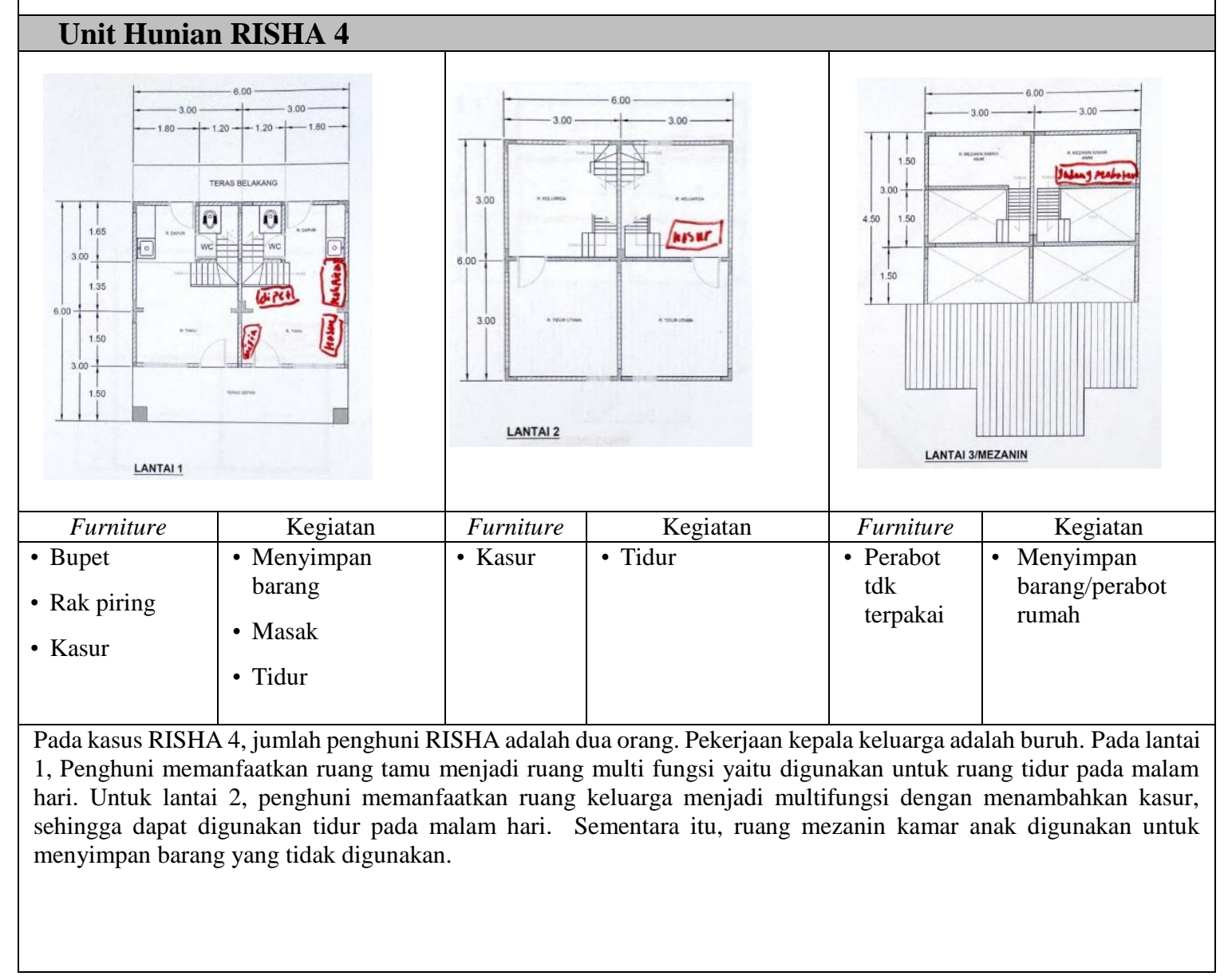




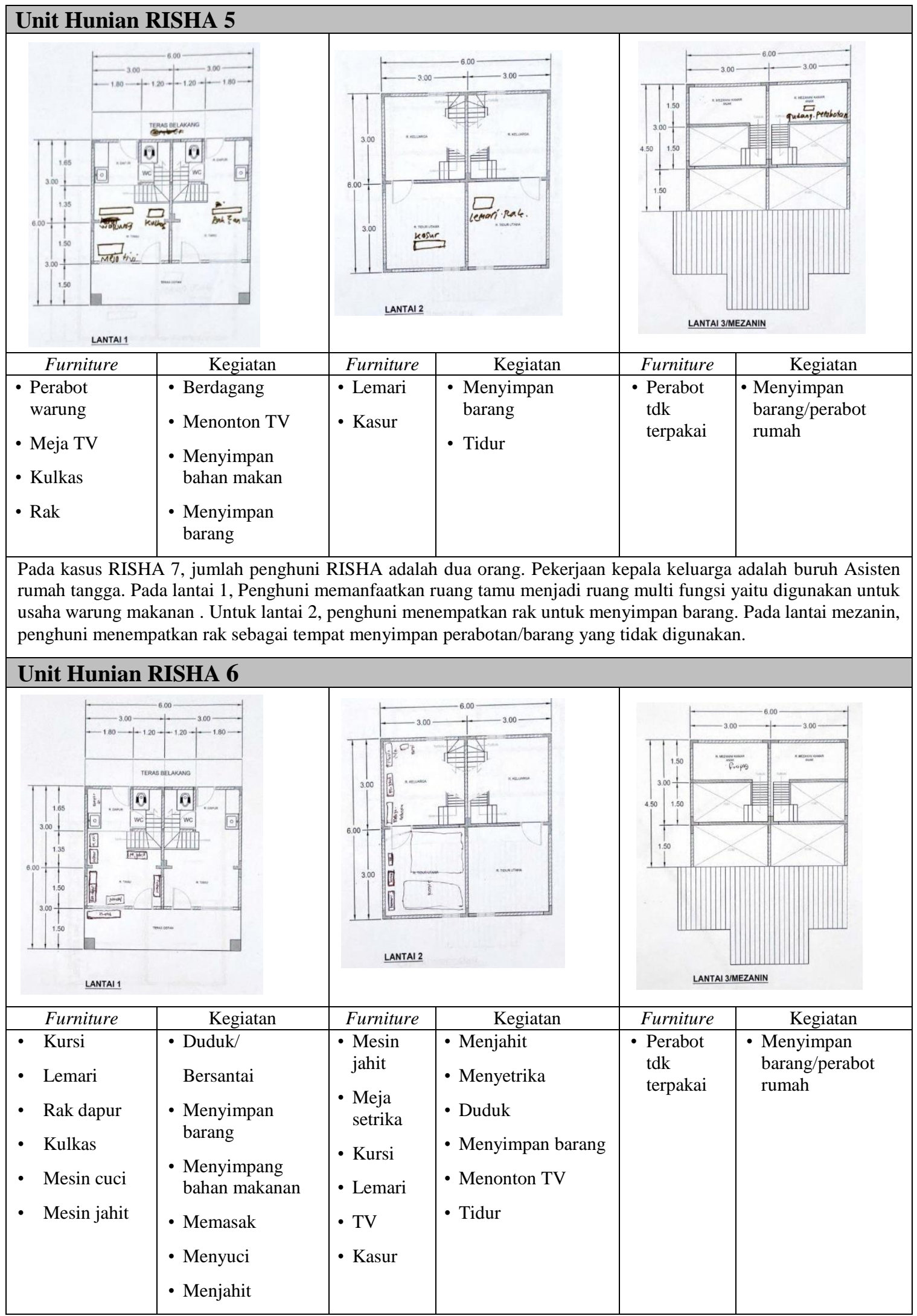




\begin{abstract}
Pada kasus RISHA 7, jumlah penghuni RISHA adalah enam orang. Pekerjaan kepala keluarga adalah satpam. Pada lantai 1, penghuni memfungsikan teras di depan kamar sebagai tempat menerima tamu. Penghuni memanfaatkan ruang tamu menjadi ruang multi fungsi yaitu digunakan untuk tempat bekerja(menjahit) dan mencuci. Untuk lantai 2, penghuni juga membuat ruang keluarga menjadi ruang multifungsi, dimana saar malam hari dapat digunakan sebagai ruang tidur. Pada lantai mezanin dimanfaatkan untuk menyimpan barang.
\end{abstract}

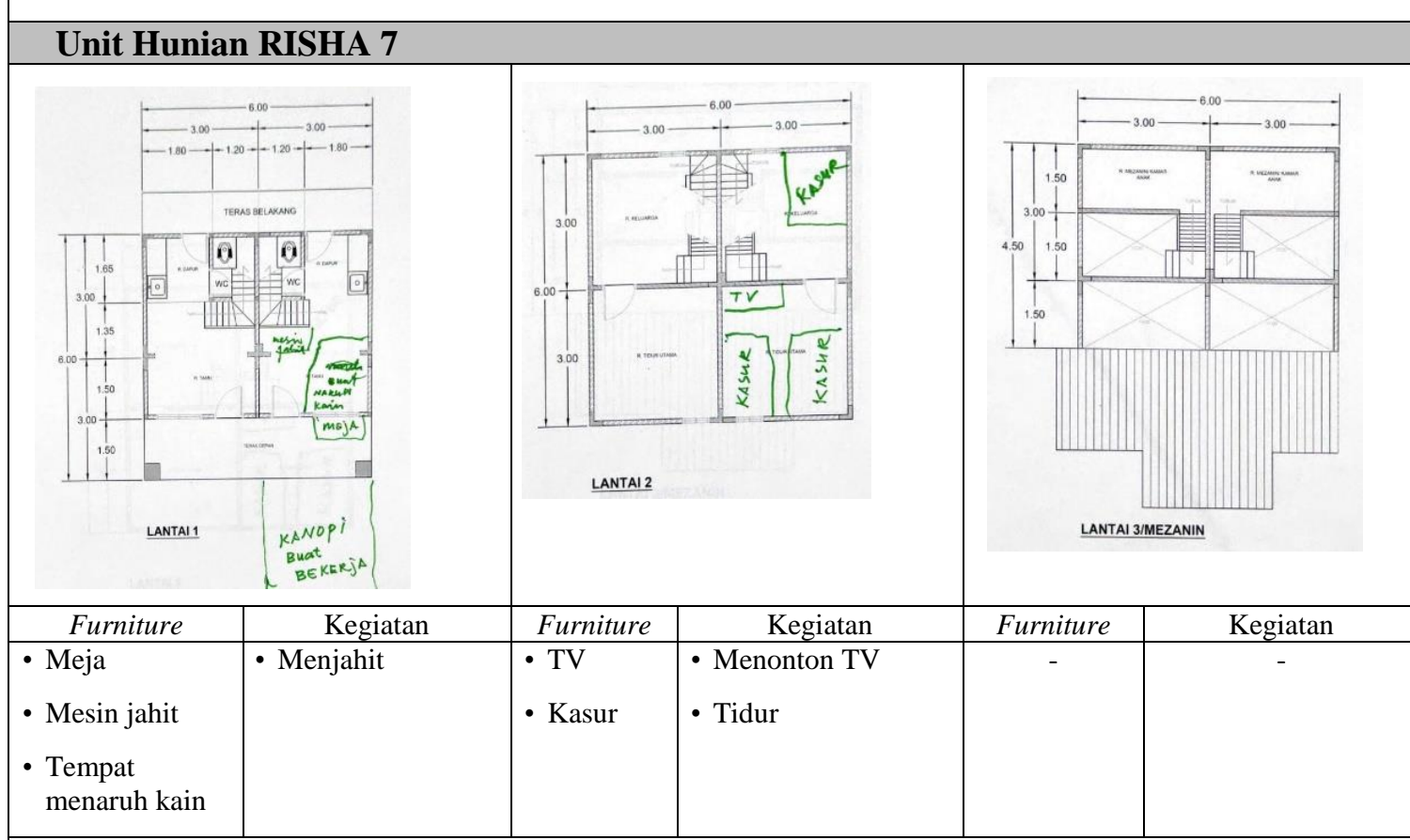

Pada kasus RISHA 7, jumlah penghuni RISHA adalah empat orang. Pekerjaan kepala keluarga adalah penjahit. Pada lantai 1, penghuni memfungsikan teras di depan kamar sebagai tempat usaha jahitan. Penghuni melakukan adaptasi by reaction dengan menambah kanopi seng di depan teras agar mengurangi resiko percikan air hujan. Penghuni memanfaatkan ruang tamu menjadi ruang multi fungsi yaitu digunakan untuk tempat bekerja. Untuk lantai 2, penghuni juga membuat ruang keluarga menjadi ruang multifungsi, dimana saar malam hari dapat digunakan sebagai ruang tidur.

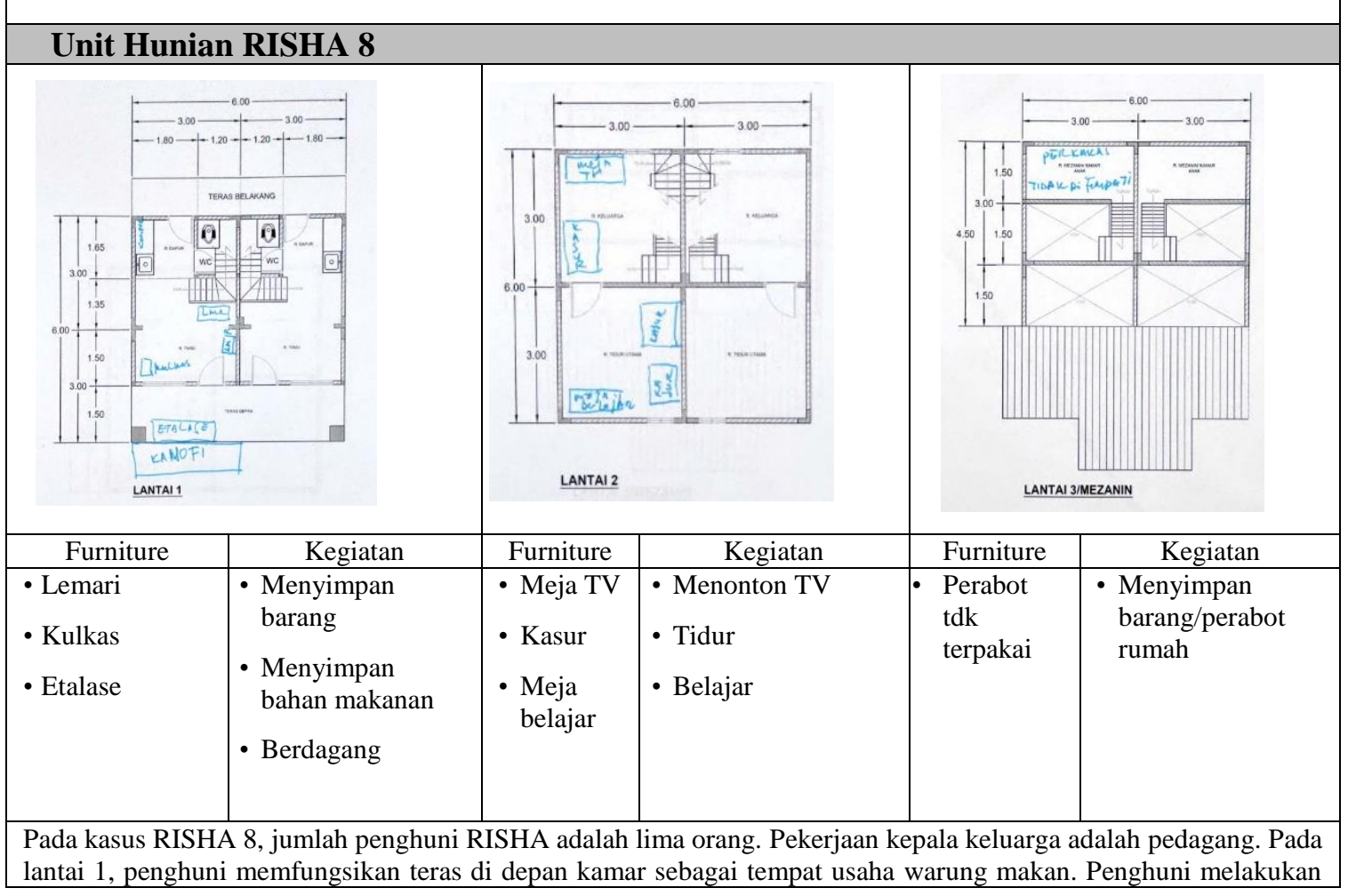


adaptasi by reaction dengan menambah kanopi seng di depan teras agar mengurangi resiko percikan air hujan. Penghuni memanfaatkan ruang tamu menjadi ruang multi fungsi yaitu digunakan untuk tempat menyimpan bahan makanan. Untuk lantai 2, penghuni juga membuat ruang keluarga menjadi ruang multifungsi, dimana saar malam hari dapat digunakan sebagai ruang tidur. Sementara itu, ruang mezanin kamar anak digunakan untuk menyimpan barang yang tidak digunakan.

Denah hunian Sub komunal RISHA dengan ukuran modul $3 \mathrm{~m}$ x $6 \mathrm{~m}$, memudahkan penghuni untuk melakukan penyesuaian sesuai kebutuhan masing-masing. Adaptasi Ruang by adjusment dilakukan dengan memanfaatkan ruang-ruang yang tersedia sesuai kebutuhan tanpa merubah secara fisik. Adaptasi dilakukan dengan cara merubah fungsi ruang atau dengan membuat ruang multifungsi (ruang dibuat fleksibel). Sebagian besar perubahan ruang dilakukan pada ruang tamu pada lantai satu dan ruang keluarga pada lantai 2. Ada yang memfungsikan ruang tamu menjadi ruang usaha, atau menjadikan ruang tamu menjadi ruang multifungsi (dapat digunakan untuk fungsi ruang tidur). Ruang keluarga di lantai dua juga sering dijadikan ruang multifungsi, sebagai ruang tidur atau ruang penyimpanan barang.

Adaptasi Ruang by reaction penghuni Sub Komunal RISHA Semanggi dilakukan dengan menambah sekat semi permanen pada ruang tidur. Fenomena ini tampak pada ruang tidur lantai dua dibeberapa unit hunian RISHA. Penghuni memanfaatkan elemen furniture seperti almari/rak penyimpanan barang sebagai sekat semi permanen. Fungsi teras juga tampak berubah, bagi para penghuni RISHA yang memfungsikan teras rumah untuk usaha. Selain meletakkan elemen semi permanen seperti lemari/etalase, mereka juga menambah kanopi seng di depan teras sebagai pelindung tambahan agar saat terjadi hujan tidak tampias ke teras. Selain itu adaptasi ruang by reaction juga dilakukan penghuni RISHA dengan menambah tempat jemuran di depan unit RISHA untuk menjemur pakaian.

Sedangkan terkait dengan Adaptasi Ruang by withdrawal tidak teridentifikasi pada kasus unit hunian di Sub Komunal RISHA Semanggi. Karena para penghuni tidak ada yang berpindah. Para penghuni bertahan pada hunian sementara yang telah disediakan oleh Pemerintah Kota Surakarta dan mereka akan berpindah ketika hunian dan lingkungan perumahan baru telah selesai dibangun.
Sarana ruang luar seperti area bermain untuk anak tidak disediakan secara khusus pada lingkungan Sub Komunal RISHA. Sarana bermain anak memanfaatkan ruang terbuka yang ada di sekitar bangunan. Sedangkan tempat parkir kendaraan telah disediakan tempat khusus, sehingga penghuni tidak diperkenankan memarkir kendaraan di unit RISHA.

\section{KESIMPULAN}

Sub Komunal RISHA Semanggi dibangun sebagai tempat hunian sementara bagi warga yang terdampak penataan bantaran Sungai Bengawan Solo. Progres penataan dan pembangunan kembali area bantaran membutuhkan waktu dan proses yang lama. Sehingga warga terdampak perlu disediakan dan dipindahkan pada hunian sementara yang representatif dan dapat mewadahi aktivitas penghuninya secara normal. Keterbatasan unit hunian yang ditempati memberikan pengaruh perubahan perilaku penghuni sebagai suatu respon penyesuaian dengan lingkungan baru.

Adaptasi Ruang yang dilakukan oleh penghuni Sub Komunal RISHA dapat diidentifikasi dari dua tipe adaptasi yaitu adaptasi by adjusment dan adaptasi by reaction. Pertama adaptasi by adjusment, dilakukan penghuni RISHA dengan cara menyesuaikan diri dengan lingkungan baru melalui pengoptimalan ruang-ruang yang tersedia dengan cara merubah fungsi ruang atau membuat ruang multifungsi yang dapat mewadahi berbagai macam kegiatan. Kedua, adaptasi by reaction dilakukan penghuni RISHA dengan cara menambah elemen semi fix sebagai partisi/sekat di dalam ruang seperti dengan menambahkan perabot lemari. Perubahan secara fisik juga dilakukan dengan menambah kanopi seng di teras depan/teras belakang untuk mengakomodasi kegiatan baru yang muncul di teras (seperti kegiatan/aktivitas usaha). 


\section{UCAPAN TERIMAKASIH}

Penelitian ini merupakan bagian dari kegiatan Hibah Grup Riset (HGR) Urban Rural Design and Conservation (URDC) Prodi Arsitektur UNS, dilakukan dengan dukungan pendanaan dari LPPM UNS. Terimakasih kepada Arsitek Komunitas Surakarta, tokoh masyarakat dan penghuni Risha Semanggi yang telah berkolaborasi dan berpartisipasi dalam penelitian ini.

\section{REFERENSI}

Fang, F., Bambang Susetyarto, M., Lianto, F., \& Siwi, S. H. (2020). Study of lighting, humidity, and ventilation in RISHA design at Kampung Deret Petogogan, Jakarta. IOP Conference Series: Materials Science and Engineering, 1007(1), 6-12. https://doi.org/10.1088/1757899X/1007/1/012080

Ghozali, I. (2018). Adaptasi Ruang Terhadap Perilaku Penghuni Pada Rumah Susun Penjaringansari Surabaya. Jurnal Envirotek, 9(1). https://doi.org/10.33005/envirotek.v9i1.1 047.

Hijah, S. N., \& Komarudin, M. (2019). Rehabilitasi dan Rekonstruksi Pasca Gempa Lombok Provinsi Nusa Tenggara Barat Tahun 2018. Prosiding Seminar Nasional Teknik Sipil 2019 Fakultas Teknik Universitas Muhammadiyah Surakarta, 1-8.

Irwin Altman, Amos Rapoport, J. F. W. (1980). Human Behavior and Environment, Advances in Theory and Research, Volume 4 Environment an Culture. Plenum Press. https://doi.org/10.1007/978-1-48990451-5

Kamsuta, Irawanto, E., Rahmawati, H. V., \& Widayanti, B. H. (2020). Efektivitas Pembangunan Rumah Risha, Rika dan Riko (3R) Bagi Masyarakat Terdampak Gempa. Jurnal Planoearth, 5(1), 20. https://doi.org/10.31764/jpe.v5i1.2178

Luthfiah. (2010). Perubahan bentuk dan fungsi hunian pada rumah susun pasca penghunian. Journal Ruang, 2(September).

http://jurnal.untad.ac.id/jurnal/index.php/
RUANG/article/view/728

Noverti, R. S., Purwono, E. H., \& Martiningrum, I. (2014). Perancangan Bangunan Instan Fabrikasi. Jurnal Mahasiswa Jurusan Arsitektur, 2(2), 114.

Pramantha, R. Q. (2019). Penataan Permukiman Kumuh Dengan Teknologi Risha Di Kampung Deret Petogogan, Jakarta Selatan. Jurnal Ilmiah Desain \& Konstruksi, 18(1), 16-26. https://doi.org/10.35760/dk.2019.v18i1.1 955

Subagijo, E., \& Suhartono, T. (2018). Model Pengembangan Kriteria Desain Rusunawa Berdasarkan Kepuasan Penghuni Studi Kasus: Rumah Susun Sederhana Sewa Kutobedah di Kota Malang. Space, 4(1), 51-64.

Surakarta, P. (2018). Rencana Penataan Kawasan Kumuh (LARAP) Semanggi RW 23 tahun 2018.

Sushanti, I. R., Ridha, R., Yuniarman, A., \& Hamdi, A. I. (2020). Strategi Penanggulangan Kerusakan Rumah Tinggal Pasca Bencana Gempa Bumi Di Kawasan Permukiman. Jurnal Planoearth PWK FT Universitas Muhammadiyah Mataram, 2, 17-24.

UN-Habitat. (2005). Financing Urban Shelter, Global Report On Human Settlements. United Nations Human Settlements Programme.

Wibowo, A. P. (2018). Mengenal Jenis-Jenis Rumah Instan Di Indonesia Dan Kendala Yang Dihadapi Dalam Memasarkannya. Jurnal Muara Sains, Teknologi, Kedokteran Dan Ilmu Kesehatan, 2(2), 446. https://doi.org/10.24912/jmstkik.v2i2.161 3 